\title{
Thermoelectric Transport Properties of Naturally Nanostructured Ga- ZnO Ceramics: Effect of Point Defect and Interfaces
}

\author{
Xin Liang* \\ School of Engineering and Applied Sciences, Harvard University, Cambridge, \\ Massachusetts 02138, United States
}

\begin{abstract}
Point defects and nanoscale interfaces have been found of significant influence on the phonon and electrical transport properties. In the preset work, we present the high temperature thermoelectric properties of naturally nanostructured $\mathrm{Ga}-\mathrm{ZnO}$ ceramics synthesized by sparking plasma sintering process. By varying the $\mathrm{GaO}_{1.5}$ doping concentration, compositionally dependent structures were formed, from point defected solid solution to nanostructures with superlattices and nanotwins. The introduction of low $\mathrm{GaO}_{1.5}$ concentration increases both electron and point defect concentrations, leading to significantly increased electrical conductivity while reduced thermal conductivity. The nanostructure interfaces are found to increase scattering of both charge carriers and phonons, leading to drastically reduced electronic mobility and lattice thermal conductivity. A combined analysis of electrical conductivity and Seebeck coefficient with temperature was also developed, which revealed that the dominant electron scattering
\end{abstract}

\footnotetext{
* Corresponding author: liangxin@cczu.edu.cn (X. Liang); now at School of Materials Science and Engineering, Changzhou University, Changzhou, Jiangsu 213164, China 
mechanism changes with defect concentration. We believe that this approach is also likely applicable to other thermoelectric material systems.

Keywords: ZnO; Nanostructure; Thermoelectrics; Seebeck coefficient

\section{Introduction}

Thermoelectricity has emerged as a sustainable energy conversion approach and attracts intensive research efforts. $\mathrm{ZnO}$ based materials, with the merit of oxides on chemical inertness and stability, have gained practical importance in high temperature thermoelectric applications. In addition, unlike classic thermoelectric materials such as $\mathrm{PbTe}$ with high toxicity and cost, $\mathrm{ZnO}$ is an earth abundant and environmental friendly material with controllable electrical conductivity. Thermoelectric property is commonly characterized by the figure of merit $(Z T)$, defined as $S^{2} \sigma T / \kappa$, where $S, \sigma, \kappa$ and $T$ represents Seebeck coefficient, electrical conductivity, thermal conductivity and absolute temperature. Clearly, increasing the electrical conductivity and reducing the thermal conductivity is central to improve the thermoelectric properties.

Numerous efforts have been made on improving thermoelectric properties of $\mathrm{ZnO}$, by electron doping with elements such like $\mathrm{Al}^{3+1,2,3,4}$ and $\mathrm{In}^{3+5,6,7} \cdot \mathrm{Ga}^{3+}$ doping has also been applied to enhance the electrical conductivity of $\mathrm{ZnO}{ }^{8,9,10}$, while there is few studies reported on the consequent thermoelectric transport properties, especially on the thermal conductivity and Seebeck coefficient. In addition, unlike lightly doped $\mathrm{ZnO}, \mathrm{Ga}-$

enriched $\mathrm{ZnO}$ also possesses complex nanostructures. It has been reported ${ }^{11,12,13,14,15}$ that homologous $\mathrm{Ga}_{2} \mathrm{O}_{3}(\mathrm{ZnO})_{\mathrm{k}}$ natural superlattice structures exists, especially in the $\mathrm{Ga}$ 
highly doped $\mathrm{ZnO}$, in which $k$ is an integral number basically denoting the number of $\mathrm{Zn}$ $\mathrm{O}$ layers between Ga-O layers. Such superlattices belongs to the $\mathrm{RMO}_{3}(\mathrm{ZnO})_{\mathrm{k}}$ type of homologous layered oxides 11, 16, 17, 18, 19, and very low thermal conductivity can be expected due to the phonon scattering by the $\mathrm{Zn}(\mathrm{Ga})-\mathrm{O} / \mathrm{Ga}-\mathrm{O}$ nanoscale interfaces, which is important to achieve high thermoelectric performance.

Nevertheless, a search of literature reveals that, research on Ga doped $\mathrm{ZnO}$ mostly concentrates on the electrical and optical properties ${ }^{8,15,20}$, few attempts have been made either on measuring the Seebeck coefficient or evaluating the thermal conductivity. In addition, no $\mathrm{ZnO}-\mathrm{Ga}_{2} \mathrm{O}_{3}$ binary phase diagram exists to our knowledge which can be a useful guide to engineer the phase composition and microstructure. The absence of research on investigating the thermoelectric properties of $\mathrm{Ga}-\mathrm{ZnO}$ ceramics stimulates us to conduct the present work.

In this paper, we reported the high temperature thermoelectric properties of Ga$\mathrm{ZnO}$ ceramics synthesized by wet chemistry and sol-gel combustion approach, and solidified by spark plasma sintering. We characterize the compositionally dependent defect structures and investigate the effect of point defects and interfaces on thermoelectric transport properties. In the $\mathrm{Ga}$ enriched $\mathrm{ZnO}$, we observed the naturally formed $\mathrm{Ga}_{2} \mathrm{O}_{3}(\mathrm{ZnO})_{\mathrm{k}}$ superlattice compounds and the nanotwins as well. We found that these nanoscale interfaces provides additional strong phonon scattering, leading to the drastic reduction in thermal conductivity. We developed and applied a semiconductor physics model on our electrical conductivity and Seebeck coefficient measured with temperature. In doing so, we estimated the Fermi level and the dominated electron scattering mechanism in each Ga doped $\mathrm{ZnO}$. 


\section{Experiments}

The $\mathrm{Ga}$ doped $\mathrm{ZnO}$ oxide powders were prepared using a wet chemistry gel combustion method. The commercial high purity nitrate powders, $\mathrm{Zn}\left(\mathrm{NO}_{3}\right)_{2}(99.999 \%$, Sigma Aldrich ${ }^{\circledR}$, USA) and $\mathrm{Ga}\left(\mathrm{NO}_{3}\right)_{3}\left(99.999 \%\right.$, Sigma Aldrich ${ }^{\circledR}$, USA), were prepared in solutions in distilled and deionized water. After the ionic concentration was determined, two solutions were mixed together according to the designated Ga concentration of 18 atomic percent. The mixed solutions were uniformly stirred and heated and kept at $80{ }^{\circ} \mathrm{C}$, followed by the addition of several organic fuels (acrylamide, N,N'-Methylene-bisacrylamide, 2,2'-Azobisisobutyro-nitrile and ammonium persulfate) which converted the liquid into gel. After being dried in a low temperature oven at $120{ }^{\circ} \mathrm{C}$ for 12 hours, the dehydrated gel was crushed into small pieces and sent to combustion furnace where self-assisted reaction occurred at about $600{ }^{\circ} \mathrm{C}$. The residual powders after reaction, which were mainly mixture of oxide powders and carbon, were then calcined at $800{ }^{\circ} \mathrm{C}$ for 2 hours. The calcined powders were sintered into solid pellet of $12.7 \mathrm{~mm}$ in diameter and $\sim 1.00 \mathrm{~mm}$ in thickness using our home-made current assisted densification processing system (also known as spark plasma sintering) at $900{ }^{\circ} \mathrm{C}$ for 5 min. The entire sintering process was under vacuum and with a constant compressive stress of $125 \mathrm{MPa}$. The sintered sample was annealed at $1000{ }^{\circ} \mathrm{C}$ in air for 2 hours to compensate the oxygen deficiency, followed by a thermal treatment of $1150{ }^{\circ} \mathrm{C}$ for 1 day. During the post-annealing, samples were wrapped by the oxide powders of the same composition and kept in a closed crucible to minimize the evaporation of $\mathrm{ZnO}$. As reference, pure $\mathrm{ZnO}$ solid pellet was also made from high purity commercial powders 
(99.999\%, Sigma Aldrich® , USA) using the same method and also post-annealed at $1150{ }^{\circ} \mathrm{C}$ for 1 day.

X-ray diffraction data were recorded at a Bruker® D8 Discover Diffractometer and the phase compositions were analyzed using 2011 ICDD PDF database . Raman spectroscopy was performed on a LabRAM Aramis Raman system (Horiba Jobin Yvon, Edison, $\mathrm{NJ}$ ) using the $532 \mathrm{~nm}$ excitation laser operated at room temperature. The Raman spectra were collected with a $10 \mu \mathrm{m}$ diameter laser beam on a sufficiently large area to acquire the global information. The recorded spectra were post-analyzed using a commercial software package (GRAMS, Thermo Electron Corp., Philadelphia, PA). Each spectrum was calibrated by monitoring the laser Rayleigh line at $0 \mathrm{~cm}^{-1}$.

For preparing transmission electron microscopy (TEM) observations, both sides of the specimen were mechanically polished till the thickness was reduced to $60-80 \mu \mathrm{m}$, followed by ion beam milling on a Fischione® 1010 Dual Beam Ion-Mill machine. The specimen was further cleaned on a Fischione ${ }^{\circledR} 110$ Plasma Cleaner and the high resolution TEM investigations were made on a JEOL® 2010 FEG-TEM.

Thermal conductivity $(\kappa)$ was determined from the measurement of thermal diffusivity $(\alpha)$, mass density $(\rho)$ and heat capacity $C_{p}$, using the following relation

$$
\kappa(T)=\alpha(T) \cdot \rho \cdot C_{p}(T)
$$

in which the thermal diffusivity was measured from room temperature to $800{ }^{\circ} \mathrm{C}$ in flowing Argon gas on a NETZCH Micro Flash ${ }^{\circledR}$ LFA 457 instrument. Mass density was obtained using Archimedes method and the heat capacity with temperature was calculated using the Kopp-Neumann rule from literature data ${ }^{21}$. The specimen was cut 
into the bars of $2 \times 2 \times 8 \mathrm{~mm}$ dimensions for electrical conductivity and Seebeck coefficient measurements, which were made from room temperature to $800{ }^{\circ} \mathrm{C}$ in air on a ULVAC RIKO ${ }^{\circledR}$ ZEM 3 M10 unit.

\section{Results}

The mass density of the sintered samples is reduced with the addition of $\mathrm{GaO}_{1.5}$, measured as $5.579,4.815,4.982$ and $4.871 \mathrm{~g} / \mathrm{cm}^{3}$ for pure $\mathrm{ZnO}$ and 2,4 and $18 \mathrm{~mol}$. \% $\mathrm{GaO}_{1.5}$ doped $\mathrm{ZnO}$ samples. X-ray diffraction results of all the samples annealed at $1150{ }^{\circ} \mathrm{C}$ for 1 day are presented in Figure 1, with the characteristic peaks of identified phases indicated at the bottom. Unlike $\mathrm{ZnO}$ with hexagonal structure, the $\mathrm{ZnGa}_{2} \mathrm{O}_{4}$ spinel phase has a cubic structure (ICDD\# 00-038-1240). It has a few X-ray diffraction peaks which are most distinguishable from $\mathrm{ZnO}$ in the present scan range, as indicated by the red dashed lines. The 2 mol. $\% \mathrm{GaO}_{1.5}$ doped $\mathrm{ZnO}$ basically has the $\mathrm{ZnO}$ solid solution phase without the formation of $\mathrm{ZnGa}_{2} \mathrm{O}_{4}$ spinel phase. However, apparent broadening of

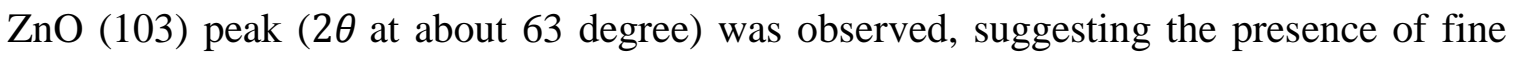
structures, which are possibly nanotwin boundaries which has been reported in the 2 mol. $\% \mathrm{GaO}_{1.5}$ doped $\mathrm{ZnO}^{13}$. In the 4 mol. $\% \mathrm{GaO}_{1.5}$ sample, in addition to the $\mathrm{ZnO}$ solid solution phase, a homologous superlattice phase $\mathrm{Ga}_{2} \mathrm{O}_{3}(\mathrm{ZnO})_{9}$ was also formed which has the orthorhombic structure (ICDD\# 00-050-0448); no $\mathrm{ZnGa}_{2} \mathrm{O}_{4}$ spinel phase was found in this sample. Both $\mathrm{Ga}_{2} \mathrm{O}_{3}(\mathrm{ZnO})_{9}$ superlattice structure and $\mathrm{ZnGa}_{2} \mathrm{O}_{4}$ spinel phase were identified in the $18 \mathrm{~mol} \% \mathrm{GaO}_{1.5}$ doped $\mathrm{ZnO}$ where $\mathrm{Ga}_{2} \mathrm{O}_{3}(\mathrm{ZnO})_{9}$ has a dominant phase fraction. 


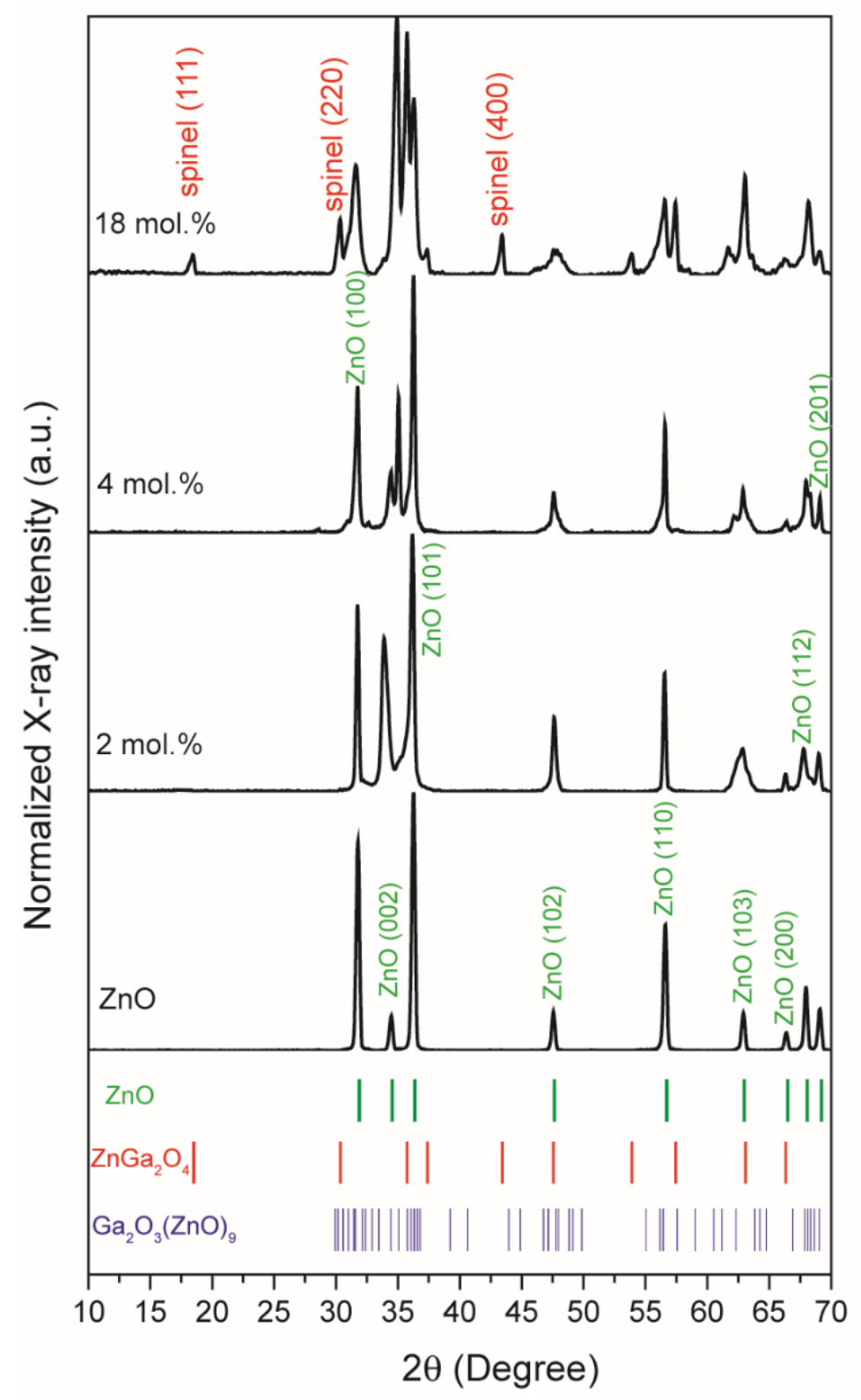

Figure 1: X-ray diffraction data of $\mathrm{Ga}$ doped $\mathrm{ZnO}$ after $1150{ }^{\circ} \mathrm{C} 1$ day thermal treatment. The characteristic peaks of $\mathrm{Ga}_{2} \mathrm{O}_{3}(\mathrm{ZnO})_{9}, \mathrm{ZnGa}_{2} \mathrm{O}_{4}$ spinel and $\mathrm{ZnO}$ phases are shown at the bottom of the figure. A few of most distinguishable $\mathrm{ZnGa}_{2} \mathrm{O}_{4}$ spinel peaks are also indicated by the vertical dashed red lines.

Raman spectra of all the samples are presented in Figure 2, with characteristic Raman modes of $\mathrm{ZnO}^{22}$ and $\mathrm{ZnGa}_{2} \mathrm{O}_{4}{ }^{23}$ structure indicated on the spectra represented by 
the labels or dashed lines of olive and red colors, respectively. With increasing gallium addition, the Raman spectrum basically remains most of the $\mathrm{ZnO}$ characteristic Raman modes, whereas a systematic broadening and shift of $\mathrm{ZnO}$ Raman modes such as $\mathrm{E}_{2}$ modes at 101 and $438 \mathrm{~cm}^{-1}$ were observed. Characteristic Raman modes of $\mathrm{ZnGa}_{2} \mathrm{O}_{4}$ spinel structure with notation of "s" are labeled on the figure according to Van Gorkom et al's report ${ }^{23}$; however, both $\mathrm{T}_{2 \mathrm{~g}}$ at $611 \mathrm{~cm}^{-1}$ and $\mathrm{E}_{\mathrm{g}}$ mode at $636 \mathrm{~cm}^{-1}$ were not observed by Preudhomme and Tarte ${ }^{24}$, and there was also discrepancy between two references on whether the $\mathrm{T}_{1 \mathrm{u}}$ mode position is at 570 or $593 \mathrm{~cm}^{-1}$. However, both peaks at $577 \mathrm{~cm}^{-1}$ and $636 \mathrm{~cm}^{-1}$, although with much reduced Raman intensity, were also observed in both 2 and $4 \mathrm{~mol} . \% \mathrm{GaO}_{1.5}$ doped $\mathrm{ZnO}$ samples, in which the spinel phases were not detected by X-ray diffraction. In addition, these Raman peaks appear much broader than those reported in the literature ${ }^{23}$. 


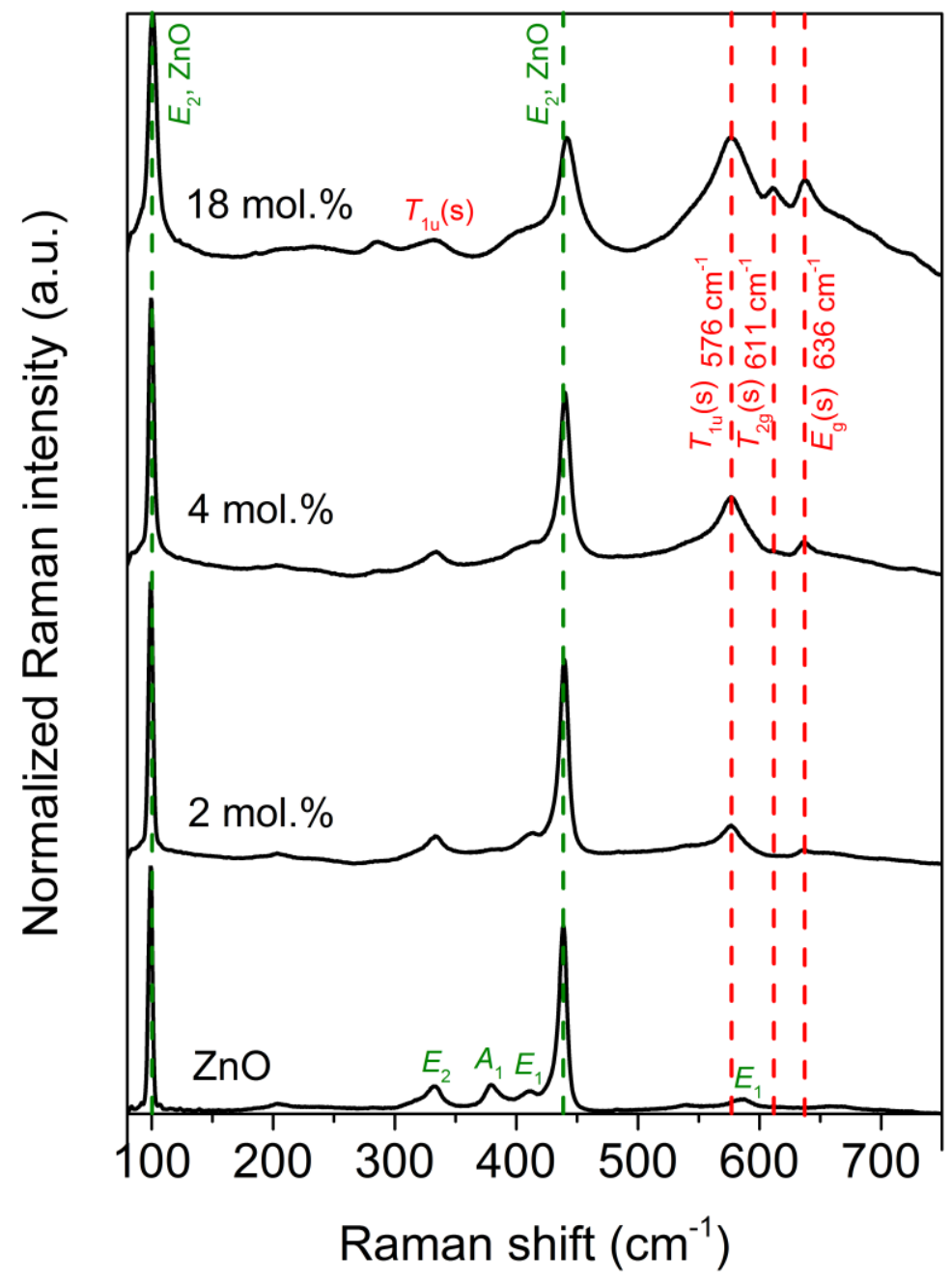

Figure 2: Raman spectra of $\mathrm{Ga}$ doped $\mathrm{ZnO}$ annealed at $1150{ }^{\circ} \mathrm{C}$ for 1 day; pure $\mathrm{ZnO}$ data was also enclosed. The characteristic Raman modes for $\mathrm{ZnO}$ and $\mathrm{ZnGa}_{2} \mathrm{O}_{4}$ spinel phase are indicated by olive and red colored labels, respectively. Raman modes of interests in the present work are also indicated by the dashed lines across all the spectra.

The homologous superlattice structures $\mathrm{Ga}_{2} \mathrm{O}_{3}(\mathrm{ZnO})_{9}$ revealed by high resolution TEM are shown in Figure 3, where nanotwin nanostructures were revealed. The twinning relationship with a crystallographic angle of $60^{\circ}$ was clearly characterized from both the 
image and the corresponding diffraction pattern as shown in Figure 3 (b); this is consistent with literature findings that twin boundaries in $\mathrm{Ga}$ doped $\mathrm{ZnO}$ are on $\{01 \overline{1} 3\}$ planes of $\mathrm{ZnO}{ }^{12,13}$. The diffuse streaks of superlattice reflection spots corresponding to the planar faults or interfaces were also observed in the electron diffraction pattern. In addition, the nanotwin boundary spacing is found to vary with locations, but has a typical length scale of $2 \sim 5 \mathrm{~nm}$.

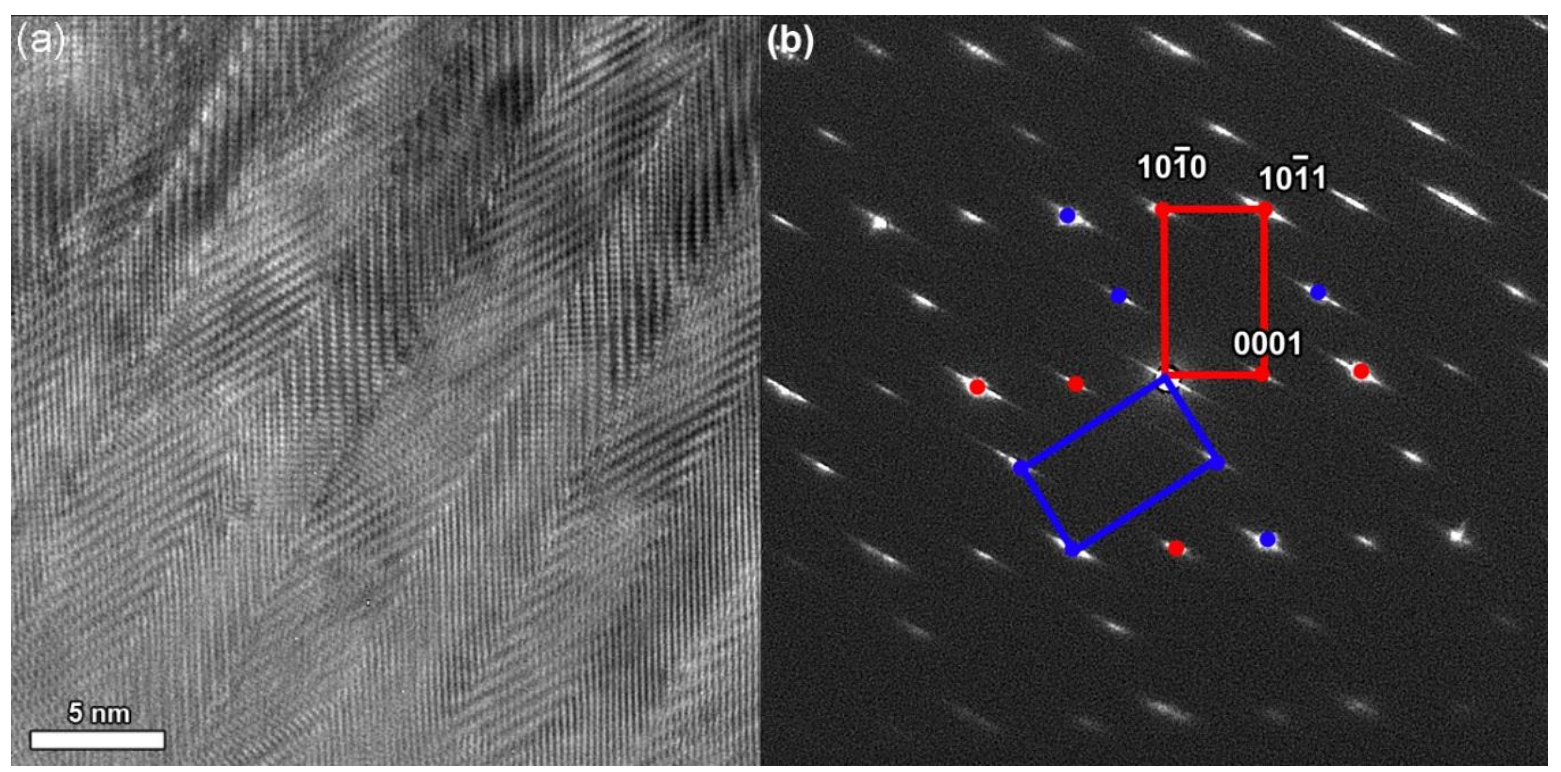

Figure 3: HRTEM image (a) and the corresponding diffraction pattern (b) of superlattice structures with nanotwins in 18 mol. \% $\mathrm{GaO}_{1.5}$ doped $\mathrm{ZnO}$. The HRTEM image reveals the nanotwin boundary with a crystallographic angel of about $60^{\circ}$. The electron diffraction pattern was taken along the $[\overline{1} 2 \overline{1} 0]$ direction, which consists of two sets of lattices; in addition, diffuse superlattice reflection streaks were also observed.

Measured thermal conductivity of $\mathrm{Ga}$ doped $\mathrm{ZnO}$ from room temperature up to $800{ }^{\circ} \mathrm{C}$ are presented in Figure 4. Also shown are the data of undoped $\mathrm{ZnO}$ for comparison. All the samples presented here were annealed at $1150{ }^{\circ} \mathrm{C}$ for 1 day. A significant reduction of thermal conductivity was observed even with a 2 mol. $\% \mathrm{GaO}_{1.5}$ 
addition. With increasing addition of $\mathrm{GaO}_{1.5}$, the thermal conductivity decreases and the temperature dependence is drastically reduced. As seen on the figure, the thermal conductivity of 18 mol. $\% \mathrm{GaO}_{1.5}$ doped $\mathrm{ZnO}$ is virtually independent on temperature. Electrical conductivities measured with temperature up to $800{ }^{\circ} \mathrm{C}$ are shown in Figure 5. All the Ga doped $\mathrm{ZnO}$ have much improved electrical conductivity than the undoped $\mathrm{ZnO}$, and the 2 mol. $\% \mathrm{GaO}_{1.5}$ doped $\mathrm{ZnO}$ demonstrates highest electrical conductivity whereas the 4 and 18 mol. $\% \mathrm{GaO}_{1.5}$ doped $\mathrm{ZnO}$ samples have similar values in the temperature range measured.

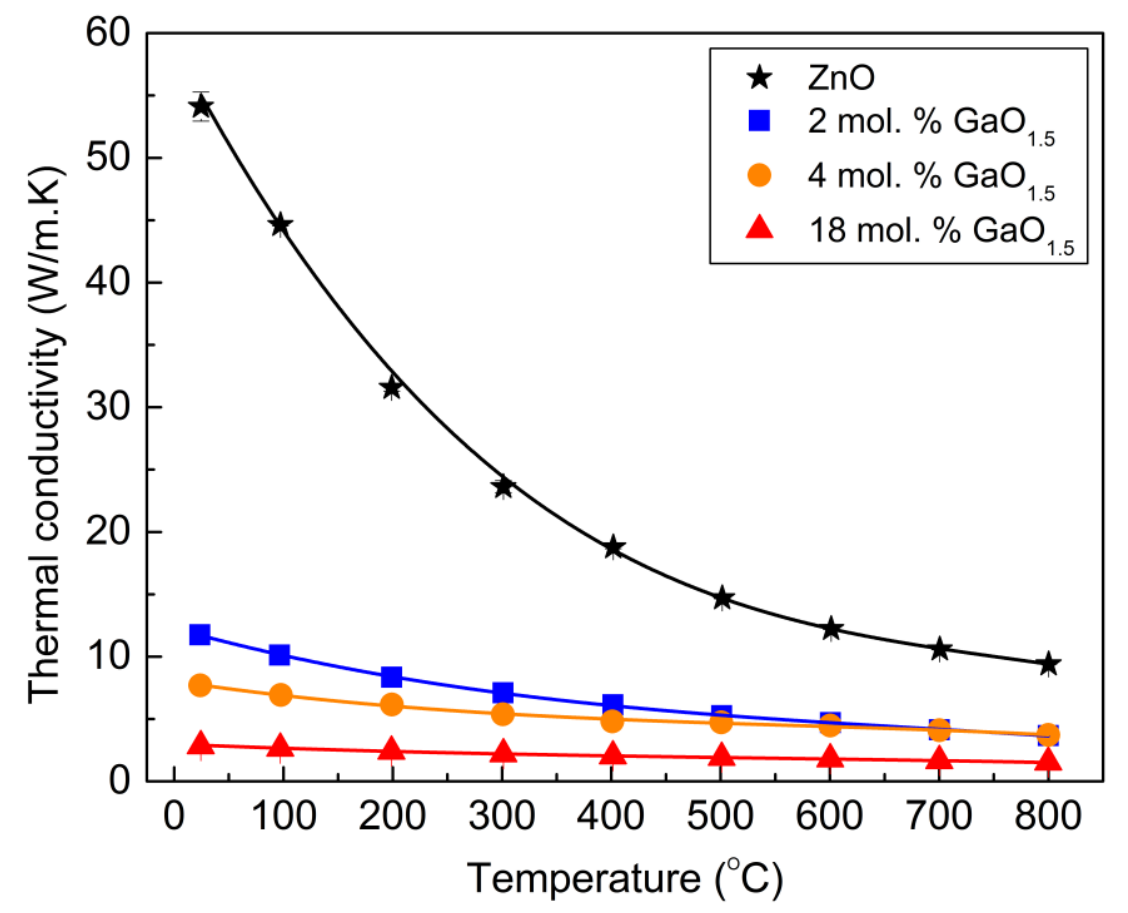

Figure 4: Thermal conductivity measured with temperature for $\mathrm{Ga}$ doped $\mathrm{ZnO}$ samples with data of undoped $\mathrm{ZnO}$ shown for comparisons, represented by scattered symbols. All the samples presented on this figure were annealed at $1150{ }^{\circ} \mathrm{C}$ for 1 day. The lines through the data points are the least square fit. 


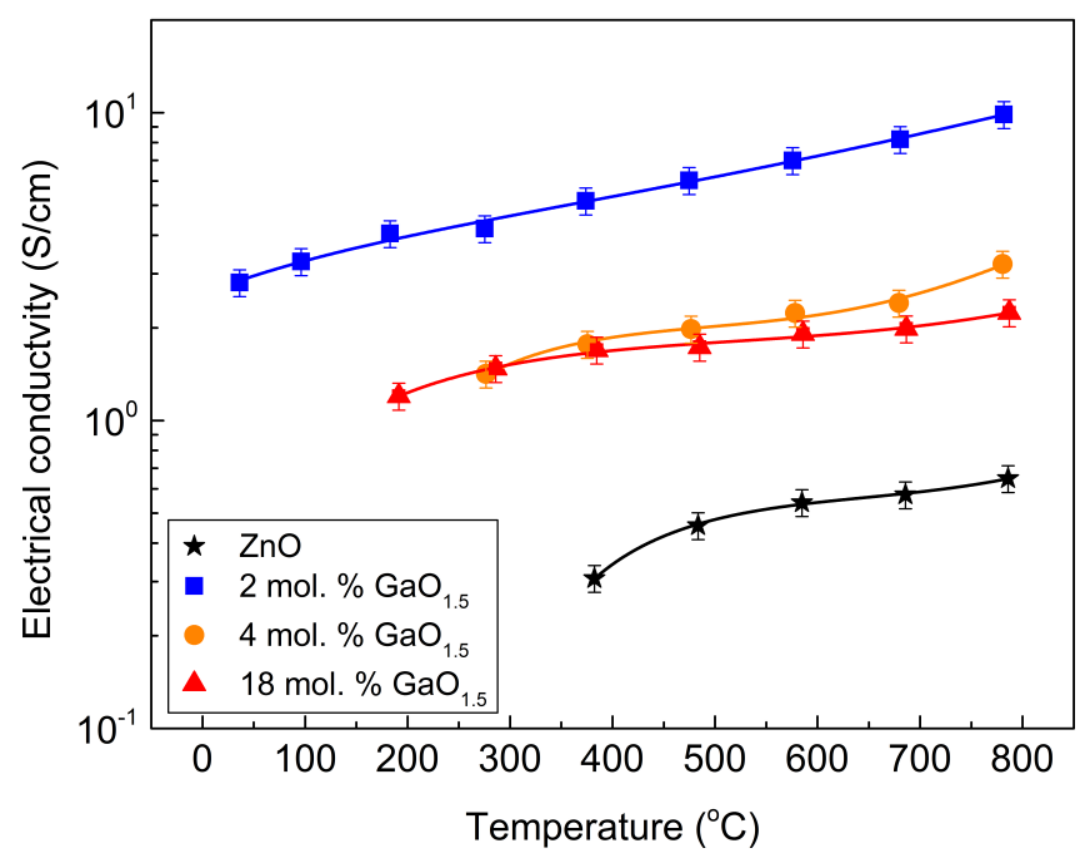

Figure 5: Electrical conductivity of $\mathrm{Ga}$ doped $\mathrm{ZnO}$ measured with temperature up to $800{ }^{\circ} \mathrm{C}$. Pure $\mathrm{ZnO}$ data are also indicated. The lines through the data points are the least square fit.

Figure 6 presents the Seebeck coefficient measured with temperature; detailed description of Seebeck coefficient analysis will be given in the later content. Across the entire temperature range of measurements, all the samples studied were found to be $n$ type semiconductors as seen from their negative values of Seebeck coefficient. Also, Seebeck coefficients of all the Ga doped $\mathrm{ZnO}$ samples studied generally increase with temperature. 


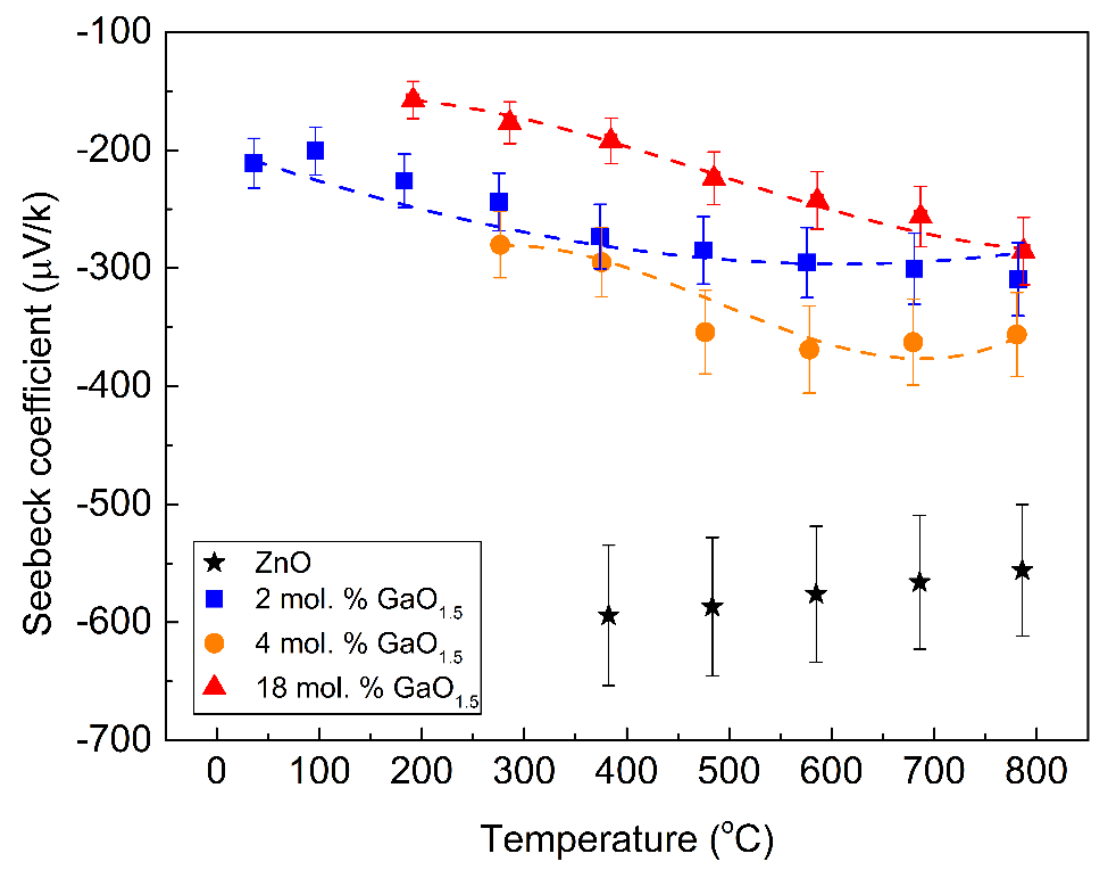

Figure 6: Seebeck coefficient of $\mathrm{Ga}$ doped $\mathrm{ZnO}$ measured with temperature up to $800{ }^{\circ} \mathrm{C}$. The experiment results are shown as scattered symbols, and the modeling fits of the measured data for extracting the information on the dominant electron scattering mechanism are represented by dashed lines with the same colors of the measurement data symbols.

\section{Discussions}

Solid Solution and Nanostructures of Ga doped $\mathrm{ZnO}$

It is unambiguous from the combined results of X-ray diffraction and Raman spectroscopy that there are $\mathrm{Ga}_{2} \mathrm{O}_{3}(\mathrm{ZnO})_{9}$ like homologous superlattice structures and $\mathrm{ZnGa}_{2} \mathrm{O}_{4}$ spinel phase (may also be with a small amount of $\mathrm{ZnO}$ solid solution phase) present in the 18 mol. $\% \mathrm{GaO}_{1.5}$ doped $\mathrm{ZnO}$. The $\mathrm{X}$-ray diffraction results clearly exclude the presence of spinel phases in both 2 and 4 mol. $\% \mathrm{GaO}_{1.5}$ doped $\mathrm{ZnO}$ samples. However, the broad Raman peaks at 577 and $636 \mathrm{~cm}^{-1}$, which were assigned to $\mathrm{T}_{1 \mathrm{u}}$ and $\mathrm{E}_{\mathrm{g}}$ modes of $\mathrm{ZnGa}_{2} \mathrm{O}_{4}$ spinel phase by Van Gorkom et al. ${ }^{23}$, were observed in all the three 
Ga doped $\mathrm{ZnO}$ samples as seen in Figure 2. It is in question whether they arise from the $\mathrm{ZnGa}_{2} \mathrm{O}_{4}$ spinel structure, considering that $\mathrm{T}_{2 \mathrm{~g}}$ mode at $611 \mathrm{~cm}^{-1}$ and $\mathrm{E}_{\mathrm{g}}$ mode at $636 \mathrm{~cm}^{-1}$ were not observed by Preudhomme and Tarte ${ }^{24}$ as well as a non-negligible discrepancy on the peak position of Raman mode at $577 \mathrm{~cm}^{-1}$. It is not impossible in both references ${ }^{23 \text {, }}$ 24 that homologous superlattice compounds $\mathrm{Ga}_{2} \mathrm{O}_{3}(\mathrm{ZnO})_{\mathrm{k}}$ formed and some of their Raman modes were mistakenly assigned to the $\mathrm{ZnGa}_{2} \mathrm{O}_{4}$ spinel phase such as those at 577 and $638 \mathrm{~cm}^{-1}$ by Van Gorkom, as the superlattice compounds $\mathrm{Ga}_{2} \mathrm{O}_{3}(\mathrm{ZnO})_{\mathrm{k}}$ were not clearly reported at that time. Also of importance is that these Raman peaks in our samples are much broader than those reported by Van Gorkom et al. ${ }^{23}$; this is similar to what we have observed in the Raman spectra of $\operatorname{In}_{2} \mathrm{O}_{3}(\mathrm{ZnO})_{\mathrm{k}}$ superlattices ${ }^{25}$.

Furthermore, in combination with X-ray diffraction results, only the Raman peak at $611 \mathrm{~cm}^{-1}$ may be undoubtedly recognized as the $\mathrm{T}_{2 \mathrm{~g}}$ mode of $\mathrm{ZnGa}_{2} \mathrm{O}_{4}$ spinel phase. As both 4 and 18 mol. $\% \mathrm{GaO}_{1.5}$ doped $\mathrm{ZnO}$ are found to have $\mathrm{Ga}_{2} \mathrm{O}_{3}(\mathrm{ZnO})_{9}$ superlattice structures by X-ray diffraction analysis, together with the HRTEM observations of the nanostructures, it therefore further increases the possibility that the two broad peaks centered at 577 and $636 \mathrm{~cm}^{-1}$ could be characteristic Raman modes of these superlattice nanostructures instead of $\mathrm{ZnGa}_{2} \mathrm{O}_{4}$ spinel phase. These two Raman peaks, with much reduced Raman intensity, are also observed in the 2 mol. $\% \mathrm{GaO}_{1.5}$ doped $\mathrm{ZnO}$ sample. With literature findings on the HRTEM observations of nanotwin boundaries in a 2 mol. \% $\mathrm{GaO}_{1.5}$ doped $\mathrm{ZnO}{ }^{13}$, as well as the X-ray (103) peak broadening we observed in this sample, it is mostly likely that nanostructures are also present in the 2 mol. $\% \mathrm{GaO}_{1.5}$ doped $\mathrm{ZnO}$. The peak information on $577 \mathrm{~cm}^{-1}$ Raman mode observed for these Ga doped $\mathrm{ZnO}$ were summarized in Table 1, including the calibrated peak position, relative peak 
intensity and the width. It can be seen that with increasing $\mathrm{Ga}_{1.5}$ addition, the $577 \mathrm{~cm}^{-1}$ Raman mode slightly moves toward large Raman shift wavenumbers. However, the most striking feature is increasing broadening and intensity of this peak with $\mathrm{Ga}_{1.5}$ addition, which implies an increasing fraction of $\mathrm{Ga}_{2} \mathrm{O}_{3}(\mathrm{ZnO})_{\mathrm{k}}$ superlattice nanostructures. In addition, a systematic shift and broadening of $\mathrm{ZnO}$ Raman modes with increasing Ga addition, such as $\mathrm{E}_{2}$ mode at 101 and $438 \mathrm{~cm}^{-1}$, was also observed, which also indicates an increasing portion of strained or defective lattice.

Table 1: Summaries of information on $577 \mathrm{~cm}^{-1}$ Raman peak.

\begin{tabular}{cccc}
\hline mol. \% $\mathrm{GaO}_{1.5}$ & Calibrated peak position, $\mathrm{cm}^{-1}$ & Relative intensity, \% & Width, $\mathrm{cm}^{-1}$ \\
\hline 2 & 577.17 & 8.56 & 22.02122 \\
4 & 577.41 & 18.21 & 28.26039 \\
18 & 577.64 & 29.80 & 31.76983 \\
\hline
\end{tabular}

These findings suggest that the Ga solubility in $\mathrm{ZnO}$ is around 2 mol. \%, similar to the findings by Wang et al. ${ }^{8}$ who reports a 2.7 mol. \% Ga solubility in $\mathrm{ZnO}$ in the temperature range of 1000 to $1200{ }^{\circ} \mathrm{C}$. Exceeding the Ga solubility in $\mathrm{ZnO}$ phase may result in one or both of the following consequences: the formation of $\mathrm{ZnGa}_{2} \mathrm{O}_{4}$ spinel phase as similar to the $\mathrm{Al}$ doped $\mathrm{ZnO}$ system 1, 3, 26, 27, 28, and/or the homologous $\mathrm{Ga}_{2} \mathrm{O}_{3}(\mathrm{ZnO})_{\mathrm{k}}$ superlattice compounds which have been reported in literatures ${ }^{11,12,13,15}$, as similar to the indium doped $\mathrm{ZnO}$ system ${ }^{19,29,30,31}$. Our XRD, Raman and HRTEM 
observations, together with literature reports, suggest that the $\mathrm{Ga}_{2} \mathrm{O}_{3}(\mathrm{ZnO})_{\mathrm{k}}$ superlattice compounds are already formed in the 2 mol. $\% \mathrm{GaO}_{1.5}$ sample whereas a detectable fraction of $\mathrm{ZnGa}_{2} \mathrm{O}_{4}$ spinel phase forms in the $18 \mathrm{~mol} \% \mathrm{GaO}_{1.5}$.

\section{Thermal Transport Properties}

Based on Wiedemann-Franz law, the electronic contribution to the thermal conductivity $\kappa_{e l}$ is given by

$$
\kappa_{e l}=L \sigma T
$$

where $L$ is Lorentz factor having a typical value of $2.4 \times 10^{-8} \mathrm{~J}^{2} \mathrm{~K}^{-2} \mathrm{C}^{-2}$ for free electrons, $\sigma$ is electrical conductivity and $T$ is the absolute temperature. However, as shown in Figure 5, electrical conductivities of all the samples across the measurement temperatures are not high enough to consider the electronic contribution to the thermal conductivity. For instance, taking the highest electrical conductivity of $\sim 10 \mathrm{~S} / \mathrm{cm}$, we found $\kappa_{e l} \approx$ $2.6 \times 10^{-2} \mathrm{~W} / \mathrm{mK}$ which is orders of magnitude smaller than the measured total thermal conductivity. Accordingly, only lattice or phonon thermal conductivity will be considered in the following discussions.

Drastic reduction of thermal conductivity with $\mathrm{Ga}$ addition was observed suggesting the enhanced phonon scatterings due to the introduction of defects. In addition, the significantly reduced temperature dependence of thermal conductivity with $\mathrm{Ga}$ addition implies the switching of dominant phonon scattering from phonon - phonon interactions, which is temperature dependent, towards a combination of point defect and interface scatterings. Although, the $\mathrm{ZnGa}_{2} \mathrm{O}_{4}$ spinel phase was present in $18 \mathrm{~mol}$. \% 
$\mathrm{GaO}_{1.5}$ doped $\mathrm{ZnO}$, it has a minor phase fraction (at most $~ 0.20$ in the 18 mol. $\% \mathrm{GaO}_{1.5}$ sample) and an average grain size of about $1 \mu \mathrm{m}$ found by our electron microscopy observations. This suggests that the role of $\mathrm{ZnGa}_{2} \mathrm{O}_{4}$ spinel phase on affecting phonon transport is much less critical as compared to the Ga-doping introduced point defects and superlattice / nanotwin interfaces that have much smaller length scale.

Using the Debye model, the general expression for thermal conductivity is the integration over the entire phonon frequency spectrum which can be further written in terms of specific heat $C(\omega)$, sound velocity $v_{S}$ and phonon mean free path $l(\omega)$,

$$
\kappa=\int \kappa(\omega) d \omega=\frac{1}{3} \int C(\omega) v_{s} l(\omega) d \omega
$$

For the point defect scattering effect, the thermal conductivity $\kappa$ is inversely proportional to the square root of the point defect phonon scattering factor $\Gamma$,

$$
\kappa \propto \Gamma^{-\frac{1}{2}}
$$

where $\Gamma$ is defined as,

$$
\Gamma=\sum_{i} f_{i}\left(1-\frac{M_{i}}{M}\right)^{2}
$$

where $M_{i}$ is the mass of a unit cell and $f_{i}$ is the fraction of the unit cells with mass $M_{i}$, and $M$ is the average mass of all cells. As seen from equation 5, the point defect scattering strength parameter depends on both defect type and concentration. Doping gallium into $\mathrm{ZnO}$ creates gallium substitutional ions on zinc sites as well as zinc vacancies for charge compensation while there are no defects on anion sites ${ }^{32}$. The corresponding defect reaction is given by, 


$$
\mathrm{Ga}_{2} \mathrm{O}_{3} \stackrel{\mathrm{ZnO}}{\longrightarrow}\left[\mathrm{Ga}_{\mathrm{Zn}}: \mathrm{V}_{\mathrm{Zn}}^{\prime \prime}: \mathrm{Ga}_{\mathrm{Zn}}^{\cdot}\right]^{\mathrm{X}}+30_{\mathrm{O}}^{\mathrm{X}}+3 \mathrm{ZnO}
$$

and the chemical formula of gallium doped $\mathrm{ZnO}$ is

$$
\left(Z n_{1-\frac{3}{2} c} G a_{c} V_{\frac{c}{2}}\right) O
$$

where $c$ is the gallium concentration in $\mathrm{ZnO}$ lattice. Taking into account both the substitutional gallium ions on zinc site and zinc vacancy, the point defect scattering strength parameter can be written as,

$$
\Gamma=c \frac{\left(M_{G a}-\overline{M_{Z n}}\right)^{2}}{2\left(\overline{M_{Z n O}}\right)^{2}}+\frac{c}{2} \frac{\left(\overline{M_{Z n}}\right)^{2}}{\left(\overline{M_{Z n O}}\right)^{2}}
$$

where $\overline{M_{Z n O}}$ is the mean mass of the doped $\mathrm{ZnO}$ formula unit and $\overline{M_{Z n}}$ is the average atomic mass on zinc site, both of which are dependent on gallium concentration $c$ in $\mathrm{ZnO}$ lattice.

Superlattice interfaces or nanotwin boundaries, as striking features of Ga doped $\mathrm{ZnO}$, also play a very important role in reducing the thermal conductivity, as cleary seen from equation 4 that thermal conductivity decreases with reducing phonon mean free path l. The lower bound for the average $\mathrm{Ga}_{2} \mathrm{O}_{3}(\mathrm{ZnO})_{\mathrm{k}}$ superlattice interface spacing $L$ can be estimated based on the chemical composition and a value of $L \sim 26 \mathrm{~nm}$ was found for the 2 mol. $\% \mathrm{GaO}_{1.5}$ doped $\mathrm{ZnO}$. Our microscopy reveals that the average nanotwin boundary spacing is about $\sim 3 \mathrm{~nm}$, while the interfacial spacing of Ga-O layers in the $\mathrm{Ga}_{2} \mathrm{O}_{3}(\mathrm{ZnO})_{9}$ superlattice phase is even smaller and is about $\frac{c_{0}}{2} \approx 1.65 \mathrm{~nm}$ where $c_{0}$ is the unit cell parameter of $\mathrm{Ga}_{2} \mathrm{O}_{3}(\mathrm{ZnO})_{9}$ modular compound ${ }^{11,12}$. With the interface spacing reducing from $\sim 26$ to $1.65 \mathrm{~nm}$, the room temperature thermal conductivity decreases from 
11.6 to $3.1 \mathrm{~W} / \mathrm{mK}$, which is about a four-fold reduction, demonstrating the nanostructure interface engineering as an effective approach to further lower the thermal conductivity.

\section{Electrical Transport Properties}

All the $\mathrm{Ga}$ doped $\mathrm{ZnO}$ samples demonstrate larger electrical conductivity as compared to the undoped $\mathrm{ZnO}$, as showns in Figure 5. This suggests that the doped $\mathrm{Ga}$ ions provide the electron donors and therefore increase the charge carrier concentration. However, through the entire measurement temperature, the electrical conductivity basically decreases with the increasing $\mathrm{Ga}$ addition, with 18 mol. \% Ga..5 doped $\mathrm{ZnO}$ having the lowest electrical conductivity. The systematic decrease of electrical conductivity with Ga addition can be correlated with the change in phase compositions and structure. As has been discussed previously, based on various characterization techniques, there is no doubt that $\mathrm{ZnGa}_{2} \mathrm{O}_{4}$ spinel phase formed in the 18 mol. $\% \mathrm{Ga}_{1.5}$ doped $\mathrm{ZnO}$. This spinel phase is a less electrical conducting phase than pure $\mathrm{ZnO}$, due to its large band gap of $4.0 \mathrm{eV}$ and electrical conductivity of $10^{-1} \mathrm{~S} / \mathrm{cm}$ at $290 \mathrm{~K}^{33}$ as compared with the band gap of $3.3 \mathrm{eV}$ for $\mathrm{ZnO}^{34}$. This is very similar to the observations on $\mathrm{Al}$ doped $\mathrm{ZnO}$ where electrical conductivity initially increases with $\mathrm{Al}$ addition but drops when the $\mathrm{Al}$ solubility in $\mathrm{ZnO}$ lattice is reached and a less conducting $\mathrm{ZnAl}_{2} \mathrm{O}_{4}$ spinel phase forms ${ }^{2}$. Furthermore, the content of superlattice or nanotwin interfaces increases with Ga addition; these nanostructures can also scatter electrons to some extent and induce an increase in electrical resistivity ${ }^{15}$. 
The superlattices are essentially interfaces of single-atomic sheets, while the nanotwins are grain boundaries. These nanoscale interfaces are basically two-dimensional or planar defects in a single-phase matrix, being obstacles for affecting electron and phonon transfer. One may also consider treating the materials as multi-phase system, the finite element method (FEM) modeling or effective medium theory, for instance, could be approaches to be used. However, the challenge then rises up that the intrinsic properties of the superlattices are mostly unavailable, since the ordered natural superlattices are usually difficult to obtain. Furthermore, the effect of the interfaces is usually not considered in these approaches ${ }^{35,36}$. The difference between these analyzing approaches is, to some extent, the length scale that we are considering. In the present work, we consider the electron transport from the microscopic scale and treat the superlattices and nanotwins as planar defects in the matrix. Whereas the 18 mol. \% $\mathrm{GaO}_{1.5}$ doped $\mathrm{ZnO}$ contains a detectable fraction of $\mathrm{ZnGa}_{2} \mathrm{O}_{4}$ spinel phase, and therefore is no longer a single-phase. While in this work, we believe that the effect of the $\mathrm{ZnGa}_{2} \mathrm{O}_{4}$ phase is relatively negligible, as can be seen as follows. First, it has a small fraction. Second, and also more importantly, the typical grain size of $\mathrm{ZnGa}_{2} \mathrm{O}_{4}$ spinel phase, which is a few micrometers, is far larger than the spacing of the superlattices and nanotwins that are a few nanometers, and therefore much less significant than the latter (the nanoscale interfaces) in affecting the thermoelectric transport, considering the electron and phonon mean free path. Accordingly, in the following content we shall analyze and discuss the thermoelectric transport properties by treating the materials as a single-phase system that consists of point and nanoscale planar defects. 
where $k_{B}$ is the Boltzmann's constant and $e$ is the electronic charge. Our observations that the Seebeck coefficient of Ga doped $\mathrm{ZnO}$ materials does not follow the temperature dependence given by equation 9 suggest that the $\mathrm{Ga}$ doped $\mathrm{ZnO}$ in the current work may no longer be non-degenerate. In the following content, we shall apply a physical model based on Seebeck coefficient to confirm this is indeed the case.

Seebeck coefficient is sensitive to the change of Fermi level and has been used to investigate the electron conduction process in semiconductor materials $39,40,41,42,43$. Fritzsche ${ }^{44}$ derived a model in which the correlation between Seebeck coefficient and Fermi level is clearly presented. For the n-type semiconductor, one has

$$
S=-\frac{k_{B}}{e}\left[\frac{E_{C}-E_{F}}{k_{B} T}+A_{C}\right]
$$

where $E_{C}$ and $E_{F}$ are conduction band edge and Fermi level, respectively. The term $A_{C}$ is given by, 


$$
A_{C}=\frac{\int_{0}^{\infty} \frac{E-E_{C}}{k_{B} T} \sigma(E) d E}{\int_{0}^{\infty} \sigma(E) d E}
$$

which is a temperature independent constant, accounting for the carriers that are distributed beyond the conduction band $E_{C}$.

It should be noted that the bandgap $E_{g}$, the conduction band edge $E_{C}$ and the Fermi level $E_{F}$ are all dependent on temperature. The change of conduction band edge $E_{C}$ with temperature associated with the bandgap $E_{g}$ change can be well approximated by a linear relationship ${ }^{45}$, according to which the term $E_{C}$ in equation 10 is replaced by $\left(E_{C}+\gamma_{g} T\right)$ where $\gamma_{g}$ is a temperature dependent density of states gap coefficient. Similarly, the shift of Fermi level $E_{F}$ with respect to temperature can be given by $\left(E_{F}+\gamma_{F} T\right)^{40,42}$ where $\gamma_{F}$ is also a temperature coefficient. In fact, the temperature dependence of Fermi level becomes drastically weak as doping or carrier concentration increases ${ }^{46}$. Accordingly, equation 10 can be written as,

$$
-S=\frac{E_{C}-E_{F}}{e}\left(\frac{1}{T}\right)+\left[\frac{\gamma_{g}-\gamma_{F}}{e}+A_{C} \frac{k_{B}}{e}\right]
$$

The above equation suggests a linear dependence of $-S$ with $1 / T$ and the slope gives the Fermi level measured from the conduction band edge. In Figure 7, the negative Seebeck coefficient $-S$ is plotted against the inverse of absolute temperature $1 / T$. The measured data are shown by the scattered symbols while the modeling fit of the data according to equation 12 are represented by the dashed lines. Generally most of the data were reasonably well fit into the model. The derived Fermi levels as measured from the conduction band edge, $E_{C}-E_{F}$, are also indicated on the figure. We found the value of $E_{C}-E_{F}$ is $+0.066 \mathrm{eV}$ for $\mathrm{ZnO},-0.049 \mathrm{eV}$ for $2 \mathrm{~mol} . \%,-0.106 \mathrm{eV}$ for 4 mol. $\%$ and - 
$0.102 \mathrm{eV}$ for $18 \mathrm{~mol} . \% \mathrm{GaO}_{1.5}$ doped $\mathrm{ZnO}$, respectively. This suggests that the Fermi level shift above the conduction band edge in all the Ga doped $\mathrm{ZnO}$ samples investigated in the current work and the materials become degenerate, which are consistent with literature findings by photoelectron spectroscopy and band structure calculations ${ }^{47}$. The Fermi level found for $\mathrm{ZnO}$ seems to be too close to the conduction band for an undoped material. However, it has been commonly found that the native defects in $\mathrm{ZnO}$ such as oxygen vacancies can significantly affect the Fermi level and electronic transport properties ${ }^{48,49}$. While with these materials degenerate, relatively positive temperature dependence of electrical conductivity is observed for all these $\mathrm{GaO}_{1.5}$ doped samples, as different from the ordinary metallic oxide semiconductors. All the very small doping bandwidth $\left(E_{F}-E_{C} \approx 0.5 \sim 1.0 \mathrm{eV}\right)$ is the major reason. Both excitation of deeper electronic defects and ionization of impurities increases with temperature. The former one increases the carrier concentration and the latter makes the temperature dependence of mobility tend to be positive, both of which contribute to the positive temperature dependence of electrical conductivity. 
Figure 7: Plot of negative Seebeck coefficient $-S$ against the inverse of absolute temperature $1 / T$. Experimental data are shown as scattered symbols and modeling fit according to equation 12 are represented by dashed lines. The derived Fermi levels estimated for each sample, as measured from conduction band edge, $E_{C}-E_{F}$, are indicated besides each set of data.

With the finding that the $\mathrm{Ga}$ doped $\mathrm{ZnO}$ in the current work are degenerate semiconductors, it is valid to adopt the Seebeck model for metallic or degenerate semiconductors. By combining it with the electrical conductivity measurements, we are able to illuminate the dominant electron scattering mechanisms in these samples. For metallic or degenerate semiconductors, the Seebeck coefficient is given by the following relation ${ }^{37,38}$,

$$
S \approx \frac{2 k_{B}^{2}}{e \hbar} m^{*} T\left(3 \pi^{2} n\right)^{-\frac{2}{3}}
$$


where $n$ is the carrier concentration and $m^{*}$ is the effective mass of charge carriers. The above equation suggests that the Seebeck coefficient is mostly controlled by the change in temperature and carrier concentration, i.e.

$$
S \propto T \cdot n(T)^{-\frac{2}{3}}
$$

It is noted that the carrier concentration $n(T)$ is also dependent on temperature $T$, which can be extracted from the temperature dependence of electrical conductivity $\sigma(T)$, according to the following equation,

$$
\sigma(T)=n(T) e \mu(T)
$$

where $\mu(T)$ is the electron mobility and is also a function of temperature ${ }^{50}$,

$$
\mu(T)=\frac{4}{3 \pi^{\frac{1}{2}}} \Gamma\left(r+\frac{5}{2}\right) \frac{e \tau_{0}\left(k_{B} T\right)^{r}}{m^{*}}
$$

in which $\Gamma$ here is the gamma function, $\tau_{0}\left(k_{B} T\right)^{r}=\tau_{e}$ is the electron relaxation time where $\tau_{0}$ and $r$ are constants for a given scattering process. The important constant in this equation is $r$ which reflects the temperature dependence of carrier mobility. The two bounds or extreme values of $r$ are $-3 / 2$ for electron scattering dominated by lattice vibrations or phonons, and 3/2 for ionized impurities dominated scattering, respectively. In compilation of the equations 13 to 16 with experimental data of electrical conductivity, the temperature dependence of Seebeck coefficient can be modelled with $r$ as the only fitting parameter. As shown in Figure 6, the best modeling fit of the temperature dependence of Seebeck coefficient for all the Ga doped $\mathrm{ZnO}$ are represented by dashed lines. The model describes reasonably well the temperature dependence of Seebeck coefficients measured in all the Ga doped $\mathrm{ZnO}$. Since both lattice phonons and impurities 
are present, the derived value of $r$ is a reflection of a combination of the two electron scattering mechanisms. The dominant mechanism can be indicated based on its sign and value.

Lattice (phonon) scattering, which mostly dominates in the undoped or lightly doped materials, is found to be the primary electron scattering mechanism in the $2 \mathrm{~mol}$. \% $\mathrm{GaO}_{1.5}$ doped $\mathrm{ZnO}$ for which a negative value of $r=-0.1$ was obtained. This suggests that electron mobility decreases with temperature, as at higher temperatures there are more phonons and therefore increased phonon scatterings that reduce the electron mobility. On the other hand, ionized impurity scattering is normally observed in the heavily doped materials and found to be governing in the 4 and 18 mol. $\% \mathrm{GaO}_{1.5}$ samples, both of which have a derived $r$ value of 0.32 . When ionized impurities are the main source of scattering, electron mobility increases with temperature as the thermal speeds of the carriers increase with temperature and therefore spends less time near an ionized impurity, leading to a reduced ion impurity scattering effect. The above combined analysis of electrical conductivity and Seebeck coefficient with temperature suggests a transition in the dominant electron scattering mechanism with Ga addition, i.e. from lattice or phonon scattering to ionized impurity scattering. Apparently taking the derived values of $r$ back to the equation 16 , the 2 mol. $\% \mathrm{GaO}_{1.5}$ sample has a negative temperature dependence of electron mobility while 4 and 18 mol. \% samples have positive temperature dependence, since the dominant electron scattering mechanism switches from the lattice vibration to the impurity or defect scattering mode. From this sense, the heavily doped sample should demonstrate more positive temperature dependence of electrical conductivity. However, the measured electrical conductivity 
data against temperature, as shown in Figure 5, is not exactly like this. The electrical conductivity of 4 and $18 \mathrm{~mol}$. $\mathrm{GaO}_{1.5}$ doped samples is relatively invariant with temperature; this is characteristic of electron tunneling. This is attributed to the presence of $\mathrm{Ga}_{2} \mathrm{O}_{3}(\mathrm{ZnO})_{\mathrm{k}}$ superlattices in the 4 and $18 \mathrm{~m} / \mathrm{o}$ Ga doped samples, which consists of Ga-O single atomic layers. Due to these high density nanoscale interfaces, electron tunneling becomes significant and takes a role in the electron transport behavior.

Based on the measured thermal conductivity, electrical conductivity and Seebeck coefficient, the figure of merit $Z T$ is readily obtained, as presented in Figure 8. Apparently, the $\mathrm{Ga}-\mathrm{ZnO}$ ceramics have demonstrated much improved thermoelectric performance over the pure $\mathrm{ZnO}$, and show compatible thermoelectric properties with other $\mathrm{ZnO}$ based binary oxide thermoelectrics, like $\mathrm{Fe}-\mathrm{ZnO}, \mathrm{Ni}-\mathrm{ZnO}$ and $\mathrm{In}-\mathrm{ZnO}$ ceramics whose literature reported $Z T$ values are also shown in Figure 8. The thermoelectric properties of $\mathrm{Ga}-\mathrm{ZnO}$ ceramics still lag far behind the metallic or semiconductor thermoelectric materials, while with the drastically reduced thermal conductivity due to the ability of forming natural nanostructures, efforts are oriented to be made on improving the electrical properties, for instance, by dual doping, to make the $\mathrm{Ga}-\mathrm{ZnO}$ ceramics potential for high temperature thermoelectric application. 


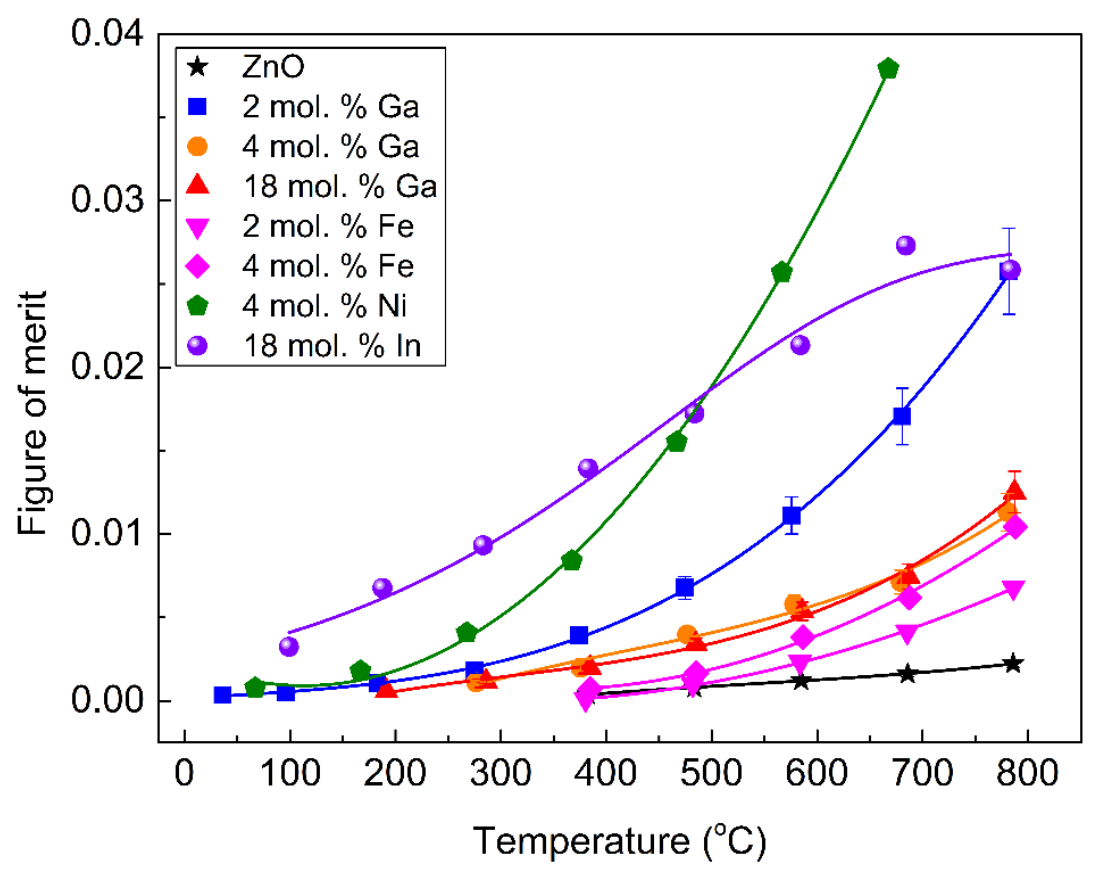

Figure 8: Figure of merit for the $\mathrm{Ga}-\mathrm{ZnO}$ ceramics with temperature. The literature reported data of single element doped $\mathrm{ZnO}$ are also presented for comparison, including $\mathrm{Fe}-\mathrm{ZnO}{ }^{25}$, 51 , Ni- $\mathrm{ZnO}$ ${ }^{52}$ and $\mathrm{In}-\mathrm{ZnO}^{25,53}$ ceramics. The lines through the data points are the least square fit for the vision guide.

\section{Conclusions}

In conclusion, high temperature thermoelectric properties and compositionally dependent structures of $\mathrm{Ga}-\mathrm{ZnO}$ ceramics are investigated. At low $\mathrm{Ga}$ addition, a $\mathrm{ZnO}$ solid solution phase is present with point defects and fine structures, which reduces thermal conductivity. Electrical conductivity was significantly improved due to the increased carrier concentration. With further increasing Ga addition beyond the solubility limit in $\mathrm{ZnO}$ lattices, a $\mathrm{Ga}_{2} \mathrm{O}_{3}(\mathrm{ZnO})_{9}$ homologous superlattice structure with nanotwins as well as $\mathrm{ZnGa}_{2} \mathrm{O}_{4}$ spinel phase are formed, both of which are less electrically conductive. The thermal conductivity, due to the additional phonon scattering by nanostructure 
interfaces, is substantially lowered in almost four-fold reduction. Analysis of the temperature dependent Seebeck measurement suggests Ga doping moves the Fermi level above the conduction band and the materials become degenerate. A combined analysis of electrical conductivity and Seebeck coefficient with temperature is developed and applied to the measured data, which reveals the change of the dominant electron scattering mechanism with $\mathrm{Ga}$ addition. The capability of tuning electrical properties and achieving low thermal conductivity with natural nanostructures makes the $\mathrm{Ga}-\mathrm{ZnO}$ ceramics potential for high temperature thermoelectric applications.

\section{Acknowledgments}

The author is grateful for Professor David R. Clarke for his valuable discussions. The author also thanks Dr. Mor Baram for assistance with the HRTEM. This work was performed in part at the Center for Nanoscale Systems (CNS) at Harvard University, a member of the National Nanotechnology Infrastructure Network (NNIN), which is supported by the National Science Foundation under NSF award no. ECS-0335765.

\section{Additional Information:}

The author declares no competing financial interests. 


\section{References}

1. Tsubota T, Ohtaki M, Eguchi K, Arai H. Thermoelectric properties of Al-doped $\mathrm{ZnO}$ as a promising oxide material for high-temperature thermoelectric conversion. Journal of Materials Chemistry 7, 85-90 (1997).

2. Guilmeau E, Maignan A, Martin C. Thermoelectric Oxides: Effect of Doping in Delafossites and Zinc Oxide. Journal of Electronic Materials 38, 1104-1108 (2009).

3. Qu XR, Wang W, Lv SC, Jia DC. Thermoelectric properties and electronic structure of Al-doped ZnO. Solid State Communications 151, 332-336 (2011).

4. Fujishiro Y, Miyata M, Awano M, Maeda K. Effect of Microstructural Control on Thermoelectric Properties of Hot-Pressed Aluminum-Doped Zinc Oxide. Journal of the American Ceramic Society 86, 2063-2066 (2003).

5. Ohta H, Seo WS, Koumoto K. Thermoelectric properties of homologous compounds in the $\mathrm{ZnO}-\mathrm{In}_{2} \mathrm{O}_{3}$ system. Journal of the American Ceramic Society 79, 2193-2196 (1996).

6. Harvey SP, Poeppelmeier KR, Mason TO. Subsolidus Phase Relationships in the $\mathrm{ZnO}-\mathrm{In}_{2} \mathrm{O}_{3}-\mathrm{SnO}_{2}$ System. Journal of the American Ceramic Society 91, 36833689 (2008).

7. Hoel CA, Mason TO, Gaillard J-F, Poeppelmeier KR. Transparent Conducting Oxides in the $\mathrm{ZnO}-\mathrm{In}_{2} \mathrm{O}_{3}-\mathrm{SnO}_{2}$ System. Chemistry of Materials 22, 3569-3579 (2010).

8. Wang RP, Sleight AW, Cleary D. High conductivity in gallium-doped zinc oxide powders. Chemistry of Materials 8, 433-439 (1996). 
9. Palmer GB, Poeppelmeier KR. Phase relations, transparency and conductivity in $\mathrm{Ga}_{2} \mathrm{O}_{3}-\mathrm{SnO}_{2}-\mathrm{ZnO}$. Solid State Sciences 4, 317-322 (2002).

10. Serier H, Demourgues A, Gaudon M. Investigation of Ga Substitution in $\mathrm{ZnO}$ Powder and Opto-Electronic Properties. Inorganic Chemistry 49, 6853-6858 (2010).

11. Kimizuka N, Isobe M, Nakamura M. Syntheses and Single-Crystal Data of Homologous Compounds, $\mathrm{In}_{2} \mathrm{O}_{3}(\mathrm{ZnO})_{\mathrm{m}}\left(\mathrm{m}=3,4\right.$, and 5), $\mathrm{InGaO}_{3}(\mathrm{ZnO})_{3}$, and $\mathrm{Ga}_{2} \mathrm{O}_{3}(\mathrm{ZnO})_{\mathrm{m}}\left(\mathrm{m}=7,8,9\right.$, and 16) in the $\mathrm{In}_{2} \mathrm{O}_{3}-\mathrm{ZnGa}_{2} \mathrm{O}_{4}-\mathrm{ZnO}$ System. Journal of Solid State Chemistry 116, 170-178 (1995).

12. Li C, Bando Y, Nakamura M, Kurashima K, Kimizuka N. Structure analysis of new homologous compounds $\mathrm{Ga}_{2} \mathrm{O}_{3}(\mathrm{ZnO})_{\mathrm{m}}(\mathrm{m}=$ integer $)$ by high-resolution analytical transmission electron microscopy. Acta Crystallographica Section B 55, 355-362 (1999).

13. Barf J, Walther T, Mader W. Twin boundaries in zinc oxide with additions of gallium oxide. Interface Science 12, 213-226 (2004).

14. Michiue Y, Kimizuka N, Kanke Y. Structure of Ga2O3(ZnO)6: a member of the homologous series $\mathrm{Ga}_{2} \mathrm{O}_{3}(\mathrm{ZnO})_{\mathrm{m}}$. Acta Crystallographica Section B 64, 521-526 (2008).

15. Yoon SW, et al. Ga Ordering and Electrical Conductivity in Nanotwin and Superlattice-Structured Ga-Doped ZnO. Crystal Growth \& Design 12, 1167-1172 (2012).

16. Nakamura M, Kimizuka N, Mohri T. The phase relations in the $\mathrm{In}_{2} \mathrm{O}_{3}-\mathrm{Fe}_{2} \mathrm{ZnO}_{4}$ ZnO system at 1350 degree C. Journal of Solid State Chemistry 86, 16-40 (1990).

17. Kimizuka N, Isobe M, Nakamura M, Mohri T. Syntheses and crystallographic data of the homologous compounds $\mathrm{InFeO}_{3}(\mathrm{ZnO})_{\mathrm{m}}(\mathrm{m}=1,2,3,7,11,13,15$, and 
19) and $\mathrm{Fe}_{2} \mathrm{O}_{3}(\mathrm{ZnO})_{\mathrm{m}}\left(\mathrm{m}=8\right.$ and 9) in the $\mathrm{In}_{2} \mathrm{O}_{3}-\mathrm{ZnFe}_{2} \mathrm{O}_{4}-\mathrm{ZnO}$ system. Journal of Solid State Chemistry 103, 394-402 (1993).

18. Uchida N, Bando Y, Nakamura M, Kimizuka N. High-resolution electronmicroscopy of homologous compounds $\mathrm{InFeO}_{3}(\mathrm{ZnO})_{\mathrm{m}}$. Journal of Electron Microscopy 43, 146-150 (1994).

19. Moriga $\mathrm{T}$, et al. Phase relationships and physical properties of homologous compounds in the zinc oxide-indium oxide system. Journal of the American Ceramic Society 81, 1310-1316 (1998).

20. Bhosle V, Tiwari A, Narayan J. Electrical properties of transparent and conducting Ga doped ZnO. Journal of Applied Physics 100, (2006).

21. Barin I. Thermochemical data of pure substances. VCH (1989).

22. Damen TC, Porto SPS, Tell B. Raman Effect in Zinc Oxide. Physical Review 142, 570-574 (1966).

23. Van Gorkom GGP, Haanstra JH, v. d. Boom H. Infrared and Raman spectra of the spinel ZnGa2O4. Journal of Raman Spectroscopy 1, 513-519 (1973).

24. Preudhomme J, Tarte P. Infrared studies of spinels-III: The normal II-III spinels. Spectrochimica Acta Part A: Molecular Spectroscopy 27, 1817-1835 (1971).

25. Liang X. Structure and Thermoelectric Properties of $\mathrm{ZnO}$ Based Materials. (ed^(eds). Harvard University (2013).

26. Ohtaki M, Tsubota $\mathrm{T}$, Eguchi $\mathrm{K}$, Arai $\mathrm{H}$. High-temperature thermoelectric properties of $\left(\mathrm{Zn}_{1-\mathrm{x}} \mathrm{Al}_{\mathrm{x}}\right) \mathrm{O}$. Journal of Applied Physics 79, 1816-1818 (1996). 
27. Yoon MH, Lee SH, Park HL, Kim HK, Jang MS. Solid solubility limits of Ga and Al in ZnO. J Mater Sci Lett 21, 1703-1704 (2002).

28. Cai KF, Muller E, Drasar C, Mrotzek A. Preparation and thermoelectric properties of Al-doped $\mathrm{ZnO}$ ceramics. Mater Sci Eng B-Solid State Mater Adv Technol 104, 45-48 (2003).

29. McCoy MA, Grimes RW, Lee WE. Planar intergrowth structures in the ZnO$\mathrm{In}_{2} \mathrm{O}_{3}$ system. Philosophical Magazine a-Physics of Condensed Matter Structure Defects and Mechanical Properties 76, 1187-1201 (1997).

30. Yan Y, Pennycook SJ, Dai J, Chang RPH, Wang A, Marks TJ. Polytypoid structures in annealed $\mathrm{In}_{2} \mathrm{O}_{3}-\mathrm{ZnO}$ films. Applied Physics Letters 73, 2585-2587 (1998).

31. Liang X, Baram M, Clarke DR. Thermal (Kapitza) resistance of interfaces in compositional dependent $\mathrm{ZnO}-\mathrm{In}_{2} \mathrm{O}_{3}$ superlattices. Applied Physics Letters 102, 223903 (2013).

32. Uematsu T, Hashimoto H. Excess electron concentration of pure and doped zinc oxides. Journal of Catalysis 47, 48-54 (1977).

33. Yan Z, Takei H, Kawazoe H. Electrical Conductivity in Transparent $\mathrm{ZnGa}_{2} \mathrm{O}_{4}$ : Reduction and Surface-Layer Structure Transformation. Journal of the American Ceramic Society 81, 180-186 (1998).

34. Srikant V, Clarke DR. On the optical band gap of zinc oxide. Journal of Applied Physics 83, 5447-5451 (1998).

35. Bergman DJ, Fel LG. Enhancement of thermoelectric power factor in composite thermoelectrics. Journal of Applied Physics 85, 8205-8216 (1999). 
36. Bergman DJ, Levy O. Thermoelectric properties of a composite medium. Journal of Applied Physics 70, 6821-6833 (1991).

37. Snyder GJ, Toberer ES. Complex thermoelectric materials. Nature Materials 7, 105-114 (2008).

38. Tritt TM. Thermoelectric Phenomena, Materials, and Applications. Annual Review of Materials Research, Vol 41 41, 433-448 (2011).

39. Jonker GH. Application of combined conductivity and seebeck-effect plots for analysis of semiconductor properties. Philips Research Reports 23, 131 (1968).

40. Ambia MG, Islam MN, Hakim MO. Studies on the seebeck effect in semiconducting $\mathrm{ZnO}$ thin films. Journal of Materials Science 27, 5169-5173 (1992).

41. Ko D-K, Urban JJ, Murray CB. Carrier Distribution and Dynamics of Nanocrystal Solids Doped with Artificial Atoms. Nano Letters 10, 1842-1847 (2010).

42. Ko DK, Murray CB. Probing the Fermi Energy Level and the Density of States Distribution in PbTe Nanocrystal (Quantum Dot) Solids by TemperatureDependent Thermopower Measurements. Acs Nano 5, 4810-4817 (2011).

43. Johnson VA, Lark-Horovitz K. Theory of Thermoelectric Power in Semiconductors with Applications to Germanium. Physical Review 92, 226-232 (1953).

44. Fritzsche H. A general expression for the thermoelectric power. Solid State Communications 9, 1813-1815 (1971).

45. Emin D. Effect of temperature-dependent band shifts on semiconductor transport properties. Solid State Communications 22, 409-411 (1977). 
46. Nguyen TH, O'Leary SK. The dependence of the Fermi level on temperature, doping concentration, and disorder in disordered semiconductors. Journal of Applied Physics 88, 3479-3483 (2000).

47. Sans JA, Sánchez-Royo JF, Segura A, Tobias G, Canadell E. Chemical effects on the optical band-gap of heavily doped $\mathrm{ZnO}$ :M-III (M=Al,Ga,In): An investigation by means of photoelectron spectroscopy, optical measurements under pressure, and band structure calculations. Physical Review B 79, 195105 (2009).

48. Janotti A, Walle CGVd. Fundamentals of zinc oxide as a semiconductor. Reports on Progress in Physics 72, 126501 (2009).

49. Kingery WD. Introuduction to Ceramics, 2nd Edition edn. Wiley Interscience (1976).

50. Goldsmid HJ. Introduction to Thermoelectricity. Springer (2010).

51. Liang X. Thermoelectric Transport Properties of Fe-Enriched $\mathrm{ZnO}$ with HighTemperature Nanostructure Refinement. ACS Applied Materials \& Interfaces 7, 7927-7937 (2015).

52. Colder H, Guilmeau E, Harnois C, Marinel S, Retoux R, Savary E. Preparation of Ni-doped $\mathrm{ZnO}$ ceramics for thermoelectric applications. J Eur Ceram Soc 31, 2957-2963 (2011).

53. Liang X, Clarke DR. Relation between thermolectric properties and phase equilibria in the $\mathrm{ZnO}-\mathrm{In}_{2} \mathrm{O}_{3}$ binary system. Acta Materialia 63, 191-201 (2014). 


\section{Table}

Table 1: Summaries of information on $577 \mathrm{~cm}^{-1}$ Raman peak.

\begin{tabular}{cccc}
\hline $\begin{array}{c}\text { mol. \% } \\
\mathrm{GaO}_{1.5}\end{array}$ & Calibrated peak position, $\mathrm{cm}^{-1}$ & Relative intensity, \% & Width, $\mathrm{cm}^{-1}$ \\
\hline 2 & 577.17 & & \\
\hline 4 & 577.41 & & 2.56 \\
18 & 577.64 & 18.21 & 28.26039 \\
& & 29.80 & 31.76983 \\
\hline
\end{tabular}




\section{Figure captions:}

Figure 1: X-ray diffraction data of $\mathrm{Ga}$ doped $\mathrm{ZnO}$ after $1150^{\circ} \mathrm{C} 1$ day thermal treatment. The characteristic peaks of $\mathrm{Ga}_{2} \mathrm{O}_{3}(\mathrm{ZnO})_{9}, \mathrm{ZnGa}_{2} \mathrm{O}_{4}$ spinel and $\mathrm{ZnO}$ phases are shown at the bottom of the figure. A few of most distinguishable $\mathrm{ZnGa}_{2} \mathrm{O}_{4}$ spinel peaks are also indicated by the vertical dashed red lines.

Figure 2: Raman spectra of Ga doped $\mathrm{ZnO}$ annealed at $1150{ }^{\circ} \mathrm{C}$ for 1 day; pure $\mathrm{ZnO}$ data was also enclosed. The characteristic Raman modes for $\mathrm{ZnO}$ and $\mathrm{ZnGa}_{2} \mathrm{O}_{4}$ spinel phase are indicated by olive and red colored labels, respectively. Raman modes of interests in the present work are also indicated by the dashed lines across all the spectra.

Figure 3: HRTEM image (a) and the corresponding diffraction pattern (b) of superlattice structures with nanotwins in $18 \mathrm{~mol} \% \mathrm{GaO}_{1.5}$ doped $\mathrm{ZnO}$. The HRTEM image reveals the nanotwin boundary with a crystallographic angel of about $60^{\circ}$. The electron diffraction pattern was taken along the $[\overline{1} 2 \overline{1} 0]$ direction, which consists of two sets of lattices; in addition, diffuse superlattice reflection streaks were also observed.

Figure 4: Thermal conductivity measured with temperature for $\mathrm{Ga}$ doped $\mathrm{ZnO}$ samples with data of undoped $\mathrm{ZnO}$ shown for comparisons, represented by scattered symbols. All the samples presented on this figure were annealed at $1150{ }^{\circ} \mathrm{C}$ for 1 day. The lines through the data points are the least square fit. 
Figure 5: Electrical conductivity of $\mathrm{Ga}$ doped $\mathrm{ZnO}$ measured with temperature up to $800{ }^{\circ} \mathrm{C}$. Pure $\mathrm{ZnO}$ data are also indicated. The lines through the data points are the least square fit.

Figure 6: Seebeck coefficient of $\mathrm{Ga}$ doped $\mathrm{ZnO}$ measured with temperature up to $800{ }^{\circ} \mathrm{C}$. The experiment results are shown as scattered symbols, and the modeling fits of the measured data are represented by dashed lines with the same colors of the measurement data symbols.

Figure 7: Plot of negative Seebeck coefficient $-S$ against the inverse of absolute temperature 1/T. Experimental data are shown as scattered symbols and modeling fit according to equation 12 are represented by dashed lines. The derived Fermi levels estimated for each sample, as measured from conduction band edge, $E_{C}-E_{F}$, are indicated besides each set of data.

Figure 8: Figure of merit for the $\mathrm{Ga}-\mathrm{ZnO}$ ceramics with temperature. The literature reported data of single element doped $\mathrm{ZnO}$ are also presented for comparison, including $\mathrm{Fe}-\mathrm{ZnO}{ }^{25,51}, \mathrm{Ni}-\mathrm{ZnO}{ }^{52}$ and $\mathrm{In}-\mathrm{ZnO}{ }^{25,53}$ ceramics. The lines through the data points are the least square fit for the vision guide. 